\title{
RESEARCH OF ACETALDEHYDE QUANTITIES IN COMMERCIAL AND LABORATORY PRODUCED FERMENTED PRODUCTS
}

\author{
Suzana Stojanovska, ${ }^{1}$ Aleksandar Krstanovski, ${ }^{2}$ Julijana Tomovska ${ }^{3}$
}

\begin{abstract}
The main purpose of this research study is the determination of volatile flavoring substance acetaldehyde in some fermented, industrially manufactured dairy products, offered on the Bitola's market and the comparison with acetaldehyde quantities measured in fermented dairy products produced in laboratory conditions. Six samples of fermented dairy products (yoghurt and sour milk) were purchased from the local supermarkets and four samples were "homemade" manufactured in laboratory conditions. Results of the acetaldehyde quantities in different fermented dairy products were obtained through the observation of acetaldehyde values successively in a two week period and, in order to confirm the mutual correlation of variables, i.e. of the absorbance and concentration, calibration curve was created. The highest acetaldehyde quantities in all fermented dairy samples were measured on the first day of this research study, while after the fifteenth day of examination acetaldehyde concentration in each sample was equal to zero. Undoubtedly, certain conditions like $\mathrm{pH}$, temperature, strain ratio, etc. need to be met.
\end{abstract}

UDC classification: 637; DOI: http://dx.doi.org/10.12955/cbup.v5.1100

Keywords: acetaldehyde, aroma, fermentation, sour milk, yoghurt.

\section{Introduction}

Fermented dairy products are produced by adding cultures with thermophilic and mesophilic lactic acid bacteria (LAB) into milk. Generally, these cultures consist of Lactobacillus delbrueckii subsp. bulgaricus and Streptococcus thermophilus strains, which ferment the lactose into the lactic acid (Gelinas and Lachance, 1995; Shah, 1997; Gandhi 2006; Sfakianakis and Tzia, 2014) and produce volatile aromatic compounds (acetaldehyde, diacetyl, acetic acid and esters). They are produced in minimal quantities during biochemical ripening processes and are actually aroma and flavor carriers in fermented dairy products that deliver rich, rounded and characteristic taste of the fermented dairy products (Zonji, 1971; Marshall, 1987; Berković, 1998).

Acetaldehyde is an active carbonyl compound, which can react with amino acids in order to produce aromatic combinations. Hamdan et al. (1971) reported that acetaldehyde importance for yoghurt aroma was for the first time suggested by Pette and Lolkema in 1950, and later in 1968 by Keenan and Bills, who in their review stated that "high concentrations of acetaldehyde are necessary to produce a desirable flavor in yoghurt." In literature, a broad range of optimal acetaldehyde level exists, suggesting the characteristic aroma of the plain yoghurt. There are statements where acetaldehyde levels from 10 to $20 \mathrm{mg} \mathrm{kg}^{-1}$ are necessary for optimal taste and aroma, while there are reports implying acetaldehyde values from 21 to $41 \mathrm{mg} \mathrm{kg}^{-1}$, are required for typical yoghurt flavor (Senel et al. 2009).

Yoghurt flavor formation occurs in three main stages; glycolysis, lipolysis and proteolysis, and the first phase of glycolysis is in fact the transformation phase in which the key aromatic yoghurt compounds like acetaldehyde, diacetyl, acetone and ethanol, are produced (Van Hylckama Vlieg et al. 2007; Baran, 2012). On the other hand, Ledenbach and Marshall (2009) examined factors influencing the relationship of aromatic compounds in fermented dairy products and concluded that the culture disbalance, inappropriate temperature or ripening time, culture infection with bacteriophages, the presence of inhibitors and microbe contamination could lead to products with undesired characteristics. This was also confirmed by Rašic and Kurmann (1978) and Baranowska et al. (2006) who suggested that yoghurt need to be fermented from a $\mathrm{pH}$ of $3.8-4.4$, and optimal yoghurt taste could be obtained at $\mathrm{pH} 4.0-4.4$.

Considering above statements the main purpose of this research study is the determination of the volatile flavoring substance acetaldehyde in some fermented, industrially manufactured dairy products, offered on the Bitola's market and compared with the acetaldehyde quantities measured in fermented dairy products produced in laboratory conditions.

\footnotetext{
${ }^{1}$ University “St. Kliment Ohridski”, Faculty of Biotechnical Sciences, Bitola, R. Macedonia, stojanovskasuzana@gmail.com

${ }^{2}$ University "St. Kliment Ohridski”, Faculty of Biotechnical Sciences, Bitola, R. Macedonia, ace.1990@ hotmail.com

${ }^{3}$ University “St. Kliment Ohridski”, Faculty of Biotechnical Sciences, Bitola, R. Macedonia, dzulitomovska@yahoo.com
} 


\section{Materials and methods}

\section{Research material}

Six samples of fermented dairy products (yoghurt and sour milk) were purchased from the local supermarkets and four samples were "homemade" manufactured in laboratory conditions. As a starter culture for laboratory produced samples Lactobacillus delbrueckii subsp. bulgaricus and Streptococcus thermophilus strains were used, as well as certain quantities of already purchased fermented products. Laboratory samples were produced from 1 liter of fresh milk, first pasteurized at $89-100^{\circ} \mathrm{C}$ for 5 minutes, then with stirring cooled to $37-40^{\circ} \mathrm{C}$, and "inoculated" with $80-100 \mathrm{ml}$ of previously purchased yoghurt or sour milk. To initiate the fermentation, milk samples were left at room temperature for 4 to 6 hours. When the fermentation process was finished, samples were stored in a refrigerator at $4^{\circ} \mathrm{C}$.

Chemicals and reagents

All chemicals used for this examination had p.a. grade. The standard solution of acetaldehyde $-\mathrm{C}_{2} \mathrm{H}_{4} \mathrm{O}$ was prepared through dilution of the ampule quantity in $\mathrm{dH}_{2} \mathrm{O}$, in 1:100000 ratio. Different concentrations of working solutions, later used for the calibration curve creation, were prepared with additional dilution of the standard solution. Reagents were prepared appropriately to the instructions given in the methods.

Method and sample preparation

The determination of the acetaldehyde quantity in fermented dairy products in this paper was based on the mechanism described by Sawicki et al. (1961). This procedure, previously applied to formaldehyde quantification, includes the following steps: reaction of the aldehyde with 3-methyl-2-benzothiazolone hydrazone (A), to form the azine (B), oxidation of A to a reactive cation (C) and formation of the blue cation (D), (Figure 1).

This method underwent certain modifications by Pack et al. (1964), who have used the reaction with 3-methyl-2-benzothiazolone hydrazone to determine diacetyl, while their modification one year later was adapted for routine analysis of acetaldehyde in dairy cultures by Lindsay and Day (1965).

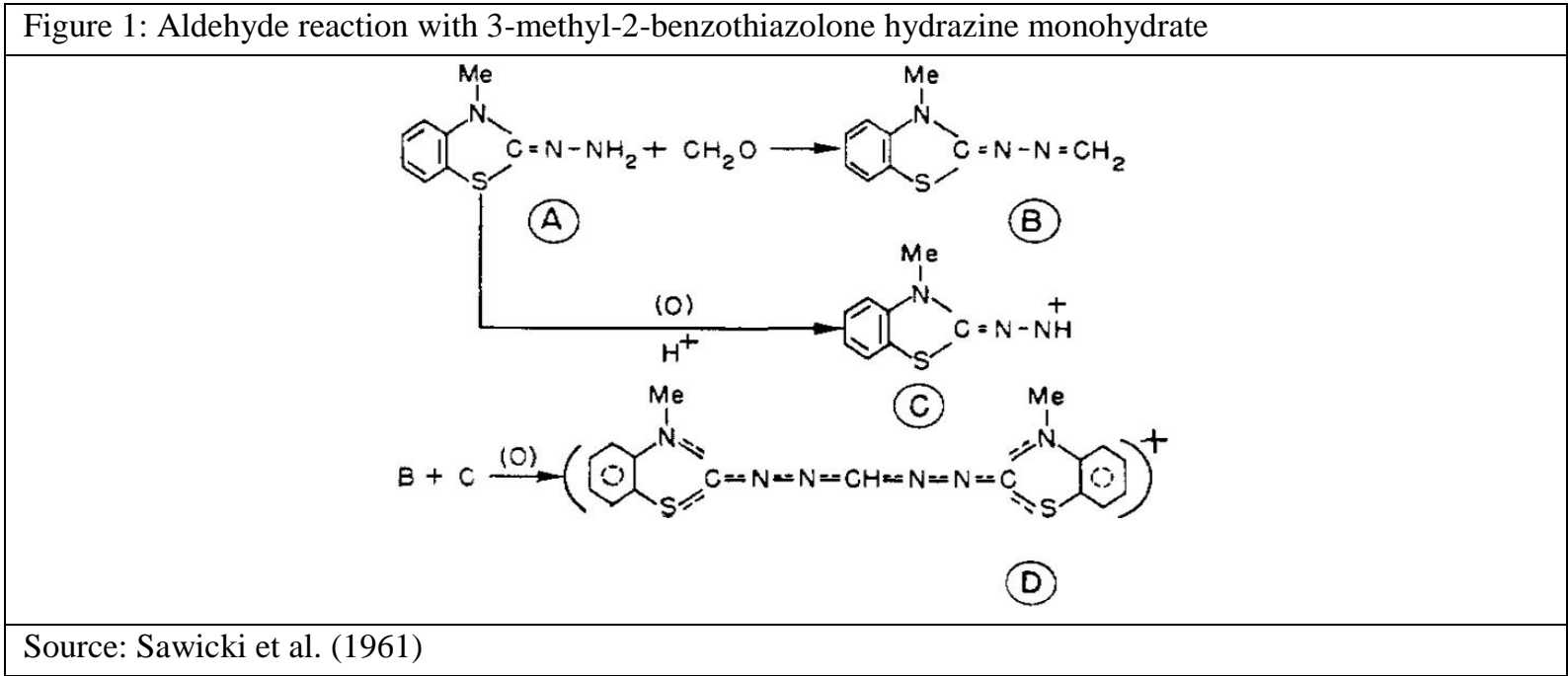

Samples were prepared according to the method reported by Carić et al. (2000). 5 to $15 \mathrm{~g}$ of research material were measured in a reagent glass $(25 \times 250 \mathrm{~mm})$. $\mathrm{HCl}$ was added into the glass in order to prevent foam formation. The next step included the addition of the following mixture to the glass content: $2.5 \mathrm{ml} \mathrm{H} \mathrm{H}_{2} \mathrm{O}+2.5 \mathrm{ml}$ water solution of 3-methyl-2-benzothiazolone hydrazone hydrochloride acid $+0.5 \mathrm{ml}$ dimethyl sulfoxide. The glass was closed with a rubber seal and placed in a water bath at $65^{\circ} \mathrm{C}$ for 60 minutes, with $\mathrm{N}_{2}$ insufflation at the same time (100-125 ml per minute). After 60 minutes, insufflation was interrupted and the glass pipe was rinsed with small quantities of $\mathrm{dH}_{2} \mathrm{O}$, inside the glass. The content was left at room temperature for 25 minutes and then $12.5 \mathrm{ml}$ solution of iron (III) chloride was added to it, thoroughly mixed and left for another 25 minutes at room temperature. In order to stop oxidation, $20 \mathrm{ml}$ of acetone was added into the reagent glass, and the content was quantitatively transferred into the volumetric flask of $50 \mathrm{ml}$ and filled with acetone to the mark. The 
flask content was centrifuged at room temperature, 3 minutes and $9000 \mathrm{RPM}$, and the supernatant was filtered (Figure 2). At the end, the filtrate was analyzed with a spectrophotometer and the color change was read at $666 \mathrm{~nm}$. The result was compared with the absorbance value obtained for a blank sample (for blank sample appropriate quantity of $\mathrm{dH}_{2} \mathrm{O}$ was used).

\begin{tabular}{|l|l|}
\hline Figure 2: Colour changes after oxidation interruption with acetone \\
\hline Source: Authors
\end{tabular}

\section{Results and discussion}

Results of acetaldehyde quantities in different fermented dairy products were obtained by observation of acetaldehyde values, successively in a two week period (Table 1), and in order to confirm the mutual correlation of variables, i.e. of the absorbance and concentration, calibration curve was created (Figure 3), indicating high positive interaction, visible from the value of coefficient square, $\mathrm{R}^{2}=$ 0.9578 (the closest value to 1 , the stronger the correlation among the variables). Dependence of acetaldehyde concentrations on examination period can be observed from Figure 4.

A general suggestion is that the aroma and flavor formation occur in the first 24 hours of the production process and this is supported by values collected in this research. The highest acetaldehyde quantities in all fermented dairy samples were measured on the first day of this research, after the fifteenth day of examination acetaldehyde concentration in each sample was equal to zero.

Many authors have also confirmed this suggestion, demonstrating that acetaldehyde formation during yoghurt production develops in the first 6 hours and this is probably due to the fast metabolic activity of the starter. According to Imhof et al. (1994); Samet-Bali et al. (2012) and Chandan (2014), formation of acetaldehyde in yoghurt takes place predominantly in the first 1-2 hours of incubation, and its level decreases in later phases. They also note that combined cultures produce higher quantities of acetaldehyde, due to proto-cooperative growth of yoghurt cultures.

Table 1: Acetaldehyde quantities in examining samples (samples purchased in supermarkets are marked with $\mathrm{S}$ and the ones produced in the laboratory are marked with $\mathrm{L}$ )

\begin{tabular}{|c|c|c|c|c|c|c|c|c|c|c|}
\hline \multicolumn{11}{|c|}{$\mathrm{C}_{2} \mathrm{H}_{4} \mathrm{O}(\mu \mathrm{g} / \mathrm{ml})$} \\
\hline \multirow{2}{*}{$\begin{array}{c}\text { Period/ } \\
\text { Days }\end{array}$} & \multicolumn{10}{|c|}{ c } \\
\hline & $1 \mathrm{~S}$ & $2 \mathrm{~S}$ & $3 \mathrm{~S}$ & $4 \mathrm{~S}$ & $5 S$ & $6 \mathrm{~S}$ & $1 \mathrm{~L}$ & $2 \mathrm{~L}$ & $3 \mathrm{~L}$ & $4 \mathrm{~L}$ \\
\hline I & 0.70 & 2.56 & 1.53 & 1.12 & 0.92 & 2.34 & 1.37 & 1.28 & 1.62 & 1.09 \\
\hline II & 0.53 & 1.28 & 0.80 & 0.79 & 0.34 & 1.33 & 0.84 & 1.06 & 1.11 & 0.79 \\
\hline III & 0.34 & 1.02 & 0.34 & 0.08 & 0.15 & 1.14 & 0.24 & 0.13 & 0.65 & 0.22 \\
\hline VII & 0.24 & 0.61 & 0.11 & 0 & 0.14 & 1.08 & 0.03 & 0 & 0.04 & 0.05 \\
\hline $\mathrm{X}$ & 0 & 0.50 & 0 & 0 & 0.05 & 0.95 & 0 & 0 & 0 & 0 \\
\hline XIII & 0 & 0.27 & 0 & 0 & 0 & 0.53 & 0 & 0 & 0 & 0 \\
\hline $\mathrm{XV}$ & 0 & 0 & 0 & 0 & 0 & 0 & 0 & 0 & 0 & 0 \\
\hline
\end{tabular}

It is important to make a parallel comparison among the values of samples purchased from supermarkets and acetaldehyde quantities of those produced in the laboratory. It is obvious that after the seventh day of analysis no concentrations were detected in laboratory manufactured samples. This could be connected to the storage period and fermentation conditions.

Güler et al. (2009) has reported that volatile compounds found in yoghurt to a large degree depend on the storage period. Acetaldehyde levels in yoghurt samples were the highest on the first day, but decreased during the period of cold storage. Considering the prolonged term, the most meaningful 
changes in all volatile compounds appeared at the end of the storage period, probably as a result of enzymatic reactions. Many authors connected (Tamime and Robinson, 2007; Güzel-Seydim et al. 2005) the lowering of acetaldehyde values during the storage period with the decrease of $\mathrm{pH}$ and increased oxidation of acetaldehyde to acetate. Özer et al. (2007) suggested that reduction of acetaldehyde concentrations during storage is induced by alcohol dehydrogenase, produced by yoghurt cultures, which converts acetaldehyde into ethanol during the storage.

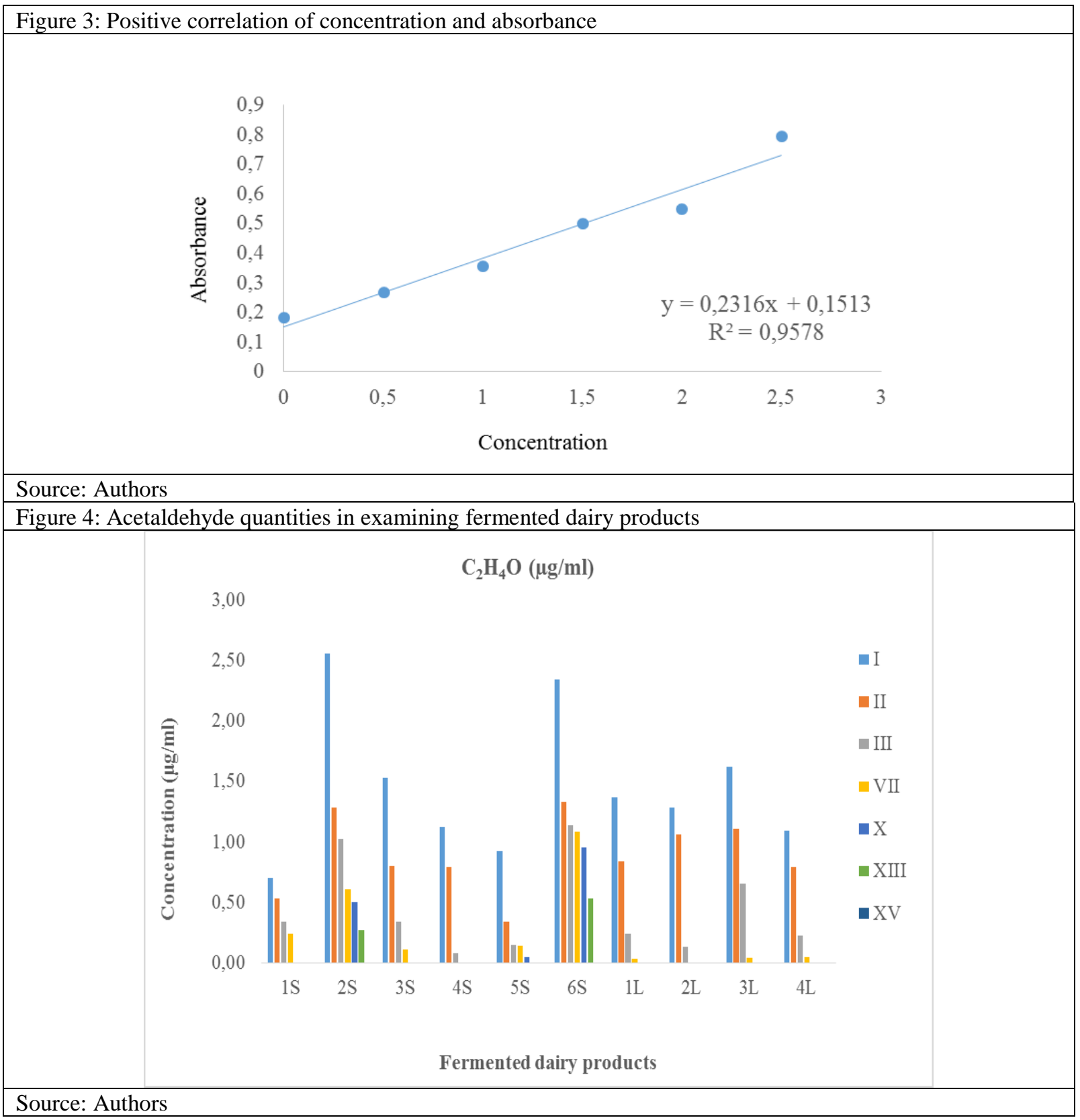

The only concern that arose regarding the storage period of samples purchased in supermarkets was the interval between the date of production and the date of delivery to the local shops.

Furthermore, when samples were sensory tested, aroma, flavor and taste of industrially produced samples were stronger and more expressive in comparison with laboratory manufactured samples. However, it is relevant that industrially manufactured samples are produced under precise and controlled conditions, with employment of sophisticated technology, which is not the case with the samples produced in the laboratory. Undoubtedly, certain conditions like $\mathrm{pH}$, temperature, strain ratio, etc. need to be met.

Proper fermentation with yoghurt culture leads to a typical aromatic compound formation and obviously acetaldehyde and other volatile aromatic compounds cannot be discussed separately, 
considering the symbiosis among LAB. Xu et al. (2015) in their research indicated that acetaldehyde quantities and other flavoring compounds are connected with the fermentation time. The longer the fermentation time, the higher concentrations of acetaldehyde and other aroma compounds in the yoghurt. According to them, sustainability of Streptococcus thermophilus has double positive effect in flavoring compounds production; on the one hand it stimulates Lactobacillus bulgaricus to produce more acetaldehyde, and on the other, it produces more diacetyl itself.

\section{Conclusion}

Summarized the results illustrate that with further research of symbiosis among Lactobacillus bulgaricus, Streptococcus thermophilus and other bacteria strains, as well as with the investigation of the balancing ratio among acetaldehyde and other aromatic volatile compounds, new possibilities for creating fermented dairy products with desired aroma and flavor characteristics are accessible. Furthermore, this includes experimentation with factors affecting the fermentation process itself. Controlled conditions in an industrial production environment, utilization of sophisticated technology and regulated storage conditions, both in plants and supermarkets, will provide fermented dairy products with high quality, positively accepted by the consumers.

\section{References}

Baran, E. (2012). Investigation on aroma profile of artisanal yoghurt starter cultures. Izmir, Turkey: Institute of technology, Graduate school of engineering and sciences.

Baranowska, M. (2006). Intensification of the synthesis of flavour compounds in yogurt by milk enrichment with precursors. Pol. J. Food Nutr. Sci., 15/56(SI 1), 5-11.

Berković, K., Lalić, L. M., Prejac, S., \& Mamić, M. (1998). Rheological characteristics of yoghurt with wheat germs addition. Mljekarstvo, 48(2), 105-114.

Carić, M., Milanović, S., \& Vucelja, D. (2000). Standardne metode analize mleka i mlečnih proizvoda [Standard methods for milk and dairy products analysis] (Tehnoloćki fakultet. vyd.). Novi Sad: Prometej.

Chandan, R. C. (2014). Dairy-Fermented products. V S. Clark, S. Jung, \& B. Lamsal, Food processing principles and applications (2nd.) 405-436. USA: John Wiley \& Sons, Ltd. doi:10.1002/9781118846315.ch18

Gandhi, D. N. (2006). Food and industrial microbiology. V Microbiology of fermented dairy products. Haryana: National Dairy Research Institute.

Gelinas, P., \& Lachance, O. (1995). Development of fermented dairy ingredients as flavor enhancers for bread. Cereal Chem., 72(1), 17-21.

Güler, Z., Tasdelen, A., Senol, H., Kerimoglu, N., \& Temel, U. (2009). The determination of volatile compounds in set-type yogurts using static headspace gas chromatographic method. GIDA, 34(3), 137-142.

Güzel-Seydim, Z. B., Sezgin, E., \& Seydim, A. C. (2005). Influences of exopolysaccharide producing cultures on the quality of plain set type yogurt. Food Control, 16(3), 205-209. doi:10.1016/j.foodcont.2004.02.002

Hamdan, I. Y., Kunsman, J. E., \& Deanne, D. D. (1971). Acetaldehyde production by combined yogurt cultures. journal of dairy science, 54(7), 1080-1082. doi:10.3168/jds.s0022-0302(71)85975-1

Imhof, R., Glättli, H., \& Bosset, J. O. (1994). Volatile organic aroma compounds produced by thermophilic and mesophilic mixed strain dairy starter cultures. LWT - Food Science and Technology, 27(5), 442-449. doi:10.1006/fstl.1994.1090

Ledenbach, L. H., \& Marshall, R. T. (2009). Microbiological spoilage of dairy products. V W. H. Sperber, \& M. P. Doyle, Compendium of the microbiological spoilage of foods and beverages, 41-67. Springer. doi:10.1007/978-1-4419-0826-1_2

Lindsey, R. C., Day, E. A., \& Sandine, W. E. (1965). Green flavor defect in lacticstarter cultures. Journal of Dairy Science, 48(7), 863-869. doi:10.3168/jds.s0022-0302(65)88352-7

Marshall, V. M. (1987). Lactic acid bacteria: starters for flavor. FEMS Microbiology Letters, 46(3), 327-336. doi:10.1016/0378-1097(87)90116-9

Özer, B., Kirmaci, H. A., Oztekin, S., Hayaloglu, A., \& Atamer, M. (2007). Incorporation of microbial transglutaminase into non-fat yogurt production. International dairy journal, 17(3), 199-207. doi:10.1016/j.idairyj.2006.02.007

Pack, M. Y., Sandine, W. E., Elliker, P. R., Day, E. A., \& Lindsay, R. C. (1964). Owades and Jakovac method for diacetyl determination in mixed-strain starters. Journal of dairy science, 47(9), 981-986. doi:10.3168/jds.s0022-0302(64)88823-8

Rašic, J. L., \& Kurmann, J. A. (1978). Yoghurt. Scientific grounds, technology, manufacture and preparations. Copenhagen: Tech. dairy Publ. House.

Samet-Bali, O., \& Attia, H. (2012). Characterization of typical Tunisian fermented milk, Rayeb. African Journal of Biotechnology, 11(25), 6744-6749. doi:10.5897/ajb11.4215

Sawicki, E., Hauser, T. R., Stanley, T. W., \& Elbert, W. (1961). The 3-methyl-2-benzothiazolone hydrazone test sensitive new methods for the detection, rapid estimation and determination of aliphatic aldehydes. Analytical Chemistry, 33(1), 93-96. doi:10.1021/ac60169a028 
Senel, E. K., Kocabas, Z., Oztekin, F. S., \& Atamer, M. (2009). An investigation on some compounds effecting aroma and flavour of strained yoghurt produced from goat milk. Tarim Bilimleri Dergisi, 15(4), 363-370.

doi:10.1501/tarimbil_0000001112

Sfakianakis, P., \& Tzia, C. (2014). Conventional and innovative processing of milk for yogurt manufacture; development of texture and flavor: A review. Foods, 3(1), 176-193. doi:10.3390/foods3010176

Shah, N. P. (1997). Bifidobacteria: Characteristics and potential for application in fermented milk products. Milchwissenschaft, 52(1), 16-20.

Tamime, A., \& Robinson, R. (2007). Background to manufacturing practise. V A. Tamime, \& R. Robinson, Yoghurt: science and technology (3rd.) 13-161. Woodhead Publishing. doi:10.1533/9781845692612.13

van Hylckama Vileg, J. E., \& Hugenholtz, J. (2007). Mining natural diversity of lactic acid bacteria for flavour and health benefits. International dairy Journal, 17(11), 1290-1297. doi:10.1016/j.idairyj.2007.02.010

Xu, Z., Li, S., Gong, G., Liu, Z., Wu, Z., \& Ma, C. (2015). Influence of different acidifying strains of Lactobacillus delbrueckii subsp. bulgaricus on the quality of yoghurt. Food science and technology research, 21(2), 263-269. doi:10.3136/fstr.21.263

Zonji, Đ. (1971). Mane i nedostaci jogurta i kiselog mleka [Defects of yogurt and sour milk]. Mljekarstvo, 21(2), 35-39. 